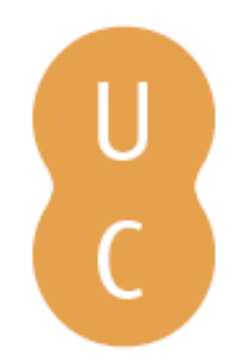

\title{
pommalina
}

\section{Desafios a uma teoria da educação na pós-modernidade}

Autor(es): $\quad$ Formosinho, Maria das Dores

Publicado por: Imprensa da Universidade de Coimbra

URL persistente:

URI:http://hdl.handle.net/10316.2/38387

DOI:

DOl:http://dx.doi.org/10.14195/978-989-26-0486-2_9

Accessed : $\quad$ 26-Apr-2023 12:59:51

A navegação consulta e descarregamento dos títulos inseridos nas Bibliotecas Digitais UC Digitalis, UC Pombalina e UC Impactum, pressupõem a aceitação plena e sem reservas dos Termos e Condições de Uso destas Bibliotecas Digitais, disponíveis em https://digitalis.uc.pt/pt-pt/termos.

Conforme exposto nos referidos Termos e Condições de Uso, o descarregamento de títulos de acesso restrito requer uma licença válida de autorização devendo o utilizador aceder ao(s) documento(s) a partir de um endereço de IP da instituição detentora da supramencionada licença.

Ao utilizador é apenas permitido o descarregamento para uso pessoal, pelo que o emprego do(s) título(s) descarregado(s) para outro fim, designadamente comercial, carece de autorização do respetivo autor ou editor da obra.

Na medida em que todas as obras da UC Digitalis se encontram protegidas pelo Código do Direito de Autor e Direitos Conexos e demais legislação aplicável, toda a cópia, parcial ou total, deste documento, nos casos em que é legalmente admitida, deverá conter ou fazer-se acompanhar por este aviso. 
João Boavida

Ángel García del Dujo

Coordenação

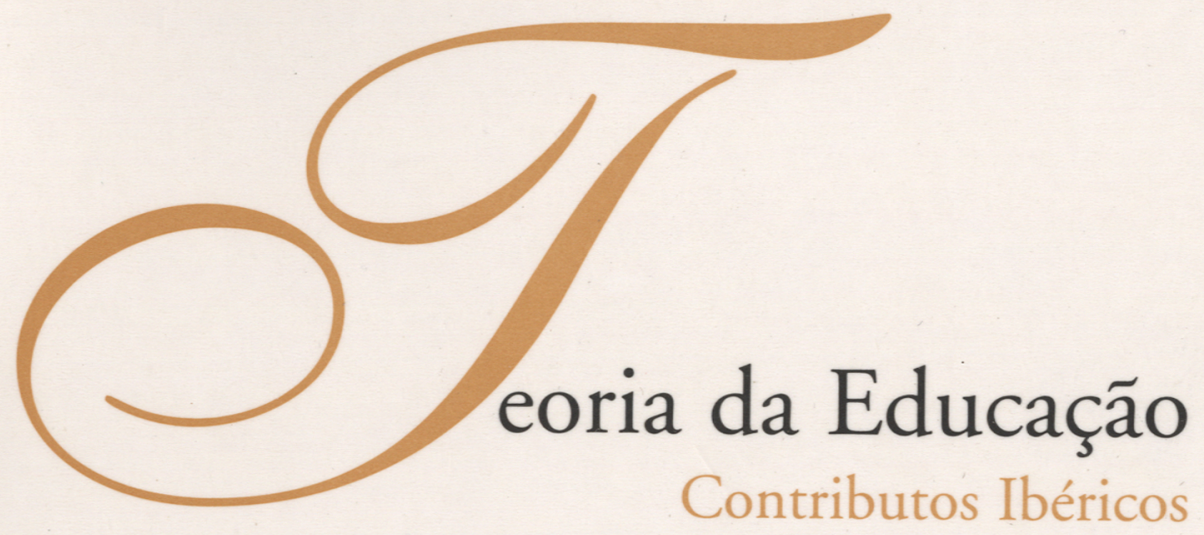


M aria das Dores Formosinho

Universidade de Coimbra

Desafios a uma Teoria da Educação na Pós-Modernidade

As Ciências da Educação são um conjunto de conhecimentos pluridisciplinares que visam, todavia, uma certa unidade de explicação ou de compreensão do fenómeno educativo. Sem esta unidade epistémica, as várias abordagens, que 0 fenómeno suscita, pulverizar-se-iam e a própria autonomia disciplinar das ciências da educação diluir-se-ia com risco da sua própria especificidade. Sem se remeterem estritamente a um plano descritivo-experimental, as Ciências da Educação foram adquirindo uma visibilidade crescente, pelo sentido pragmático de que se revestem. A teorização pedagógica visa intervir sobre o facto educativo de forma a optimizá-lo dentro das condições que são das da sua ubiquação. Neste sentido, e sem denegar 0 recorte positivista que é fundamental às várias abordagens científicas do fenómeno educativo, não se tornará possível teorizá-lo, em toda a sua abrangência, sem referenciais axiológicos e normativos que fazem da intenção de educar uma intenção planificada, de acordo com finalidades e valores. Se 0 postulado básico que configura a identidade teórica e prática da Pedagogia é a de que 0 ser humano é perfectível pela educação, haverá que perceber a historicidade das representações que tornam tangível essa perfectibilidade e a fazem vislumbrar no horizonte utópico das próprias especulações produzidas. 


\section{0 fio da modernidade nas representações e intenções pra- xeológicas da pedagogia científica.}

Como é comumente reconhecido, o discurso científico sobre a educação nasceu em estreita conexão com 0 movimento pedagógico da Educação Nova que incorporou, nas suas intenções reformadoras, os princípios de liberdade e autonomia que tipificam o pensamento secular moderno. Com efeito, e ainda que reconhecendo a hipostasiação normativo-prescritiva e supra-histórica que tem sido feita do próprio conceito de modernidade, não podemos deixar de considerar que é a partir do Iluminismo setecentista que se processa de forma extensa e consistente, no Ocidente, uma mutação assinalável nos discursos relativos ao indivíduo e à sociedade. Certo é que o Renascimento tinha já configurado um novo conceito de indivíduo e de racionalidade que denotava uma ruptura com a perspectiva teocêntrica da cultura medieval, pois 0 regresso às fontes originais do classicismo grecolatino havia feito redescobrir aos eruditos a excelência de uma cultura que se desenvolvera à margem de qualquer autoridade sobrenatural. Devido a esta influência clássica omnipresente, e sem que Deus deixe de ser pensado como 0 criador e 0 sustentáculo do universo, começa a afirmar-se 0 valor do indivíduo e da acção temporal que da sua iniciativa decorre. Neste movimento histórico de emancipação do indivíduo e secularização da cultura, 0 próprio movimento da Reforma protestante, no século XVI, desempenhou um papel importante, pois ao contestar a autoridade da Igreja, enquanto medianeira entre Deus e os homens, torna permeável 0 espírito de liberdade individual que se tornou o pilar do racionalismo moderno.

Emancipando-se da tutela teológica, a cultura moderna erege como fontes do conhecimento a experiência e a razão e, neste sentido, afiguram-se como paradigmáticos da constituição do novo espírito, no século XVII, tanto 0 experimentalismo baconiano quanto a filosofia cartesiana do cogito. Se as teses copernicanas vieram produzir uma transformação das concepções cosmológicas medievais, destronando o Homem e a Terra do centro do 
Universo, a figuração da incerteza do mundo medieval tornou-se, igualmente, reveladora na construção da filosofia cartesiana que parte do principio da dúvida metódica. Ao rejeitar como evidente qualquer outro princípio que não fosse 0 da sua própria existência, através do pensamento, Descartes não fez senão consagrar 0 movimento de emancipação da Razão que caracteriza 0 percurso da modernidade e alcança uma expansão notória no período das Luzes. A metáfora da luz, com todo o seu poder evocativo, foi utilizada no período setecentista para denotar a nova mentalidade que « exibe em acção não a razão especulativa e contemplativa do conceito clássico da ciência, mas a razão dinâmica e paroxística que intervém para transformar todas as esferas da vida humana (M. Baptista Pereira, 1989,29).

Esta crença no poder transformador da razão e na sua aplicabilidade às várias áreas da actividade humana é claramente visível no conceito de Aufklàrung (Iluminismo), proposto, em 1788, por A. Riem, que descreve a razão ilustrada como sendo «0 esforço do espírito humano para pôr à luz todos os objectos do mundo das ideias, todas as opiniões humanas e os seus resultados e tudo o que influi na humanidade, segundo os princípios de uma doutrina pura da Razão, para incremento do que é útil» (apud M. Pereira 1989,34). Como é dado a perceber nesta definição, o Iluminismo não faz da tradição autoridade, pretendendo sujeitar ao crivo da análise reflexiva todas as produções humanas, de forma a emancipar 0 sujeito das algemas mentais que 0 menorizam e obstaculizam 0 progresso. Consubstanciando a essência intelectual da modernidade, a noção de Progresso histórico que se delineia, a partir do século XVIII, transmuta profundamente a visão do tempo que começa a ser figurado como irrepetível e irreversível, por efeito da acção livre dos agentes. Sem meta definida, traçada por urna Providência divina, a Historia começa a ser conceptualizada como o locus do desenvolvimento progressivo da Razão. E se, no plano biológico, por influência das correntes evolucionistas do século XIX, o sujeito humano começa a autopercepcionar-se como fruto de urna dada evolução animal, no plano sociológico e cultural, a própria ideia de educação começa a 
ser representada como força motriz do progresso social e cultural, que há que propulsionar.

Não será, pois, por acaso que 0 discurso científico sobre a educação que nasceu numa relação estreita com 0 movimento pedagógico da Educação Nova foi, nas suas intenções e prática, um movimento reformador. Querendo fundar a prática pedagógica nos conhecimentos psicológicos sobre a criança, a Educação Nova provocou de uma maneira muito explícita uma ruptura epistémica com 0 modelo educativo tradicional que se revelava inadequado às necessidades e ao sentido de progresso que a sociedade conhecia no começo do século XX. Esta ruptura, consignada como uma «revolução pedocêntrica», na expressão de Claparède, é conduzida quer em nome da cientificidade, quer assumindo valores que são os da liberdade e autonomia dos sujeitos. 0 exemplo do Instituto J.J. Rousseau é, a este respeito, esclarecedor, porque tenta-se aí desenvolver uma pedagogia experimental, fundada sobre os dados empíricos da Psicologia, mas ao mesmo tempo todo o esforço educativo tem um fim sociopolíitico e moral. De forma explícita, a cientificidade que marca os escritos de Bovet e Claparède concilia-se sempre com intuitos reformadores a nível social, no âmbito de uma racionalidade normativa que figura 0 projecto da Modernidade. Acontece que as novas realidades tecnológico - sociais e ideologias, que marcam 0 tempo presente, tendem a fracturar os pressupostos dessa racionalidade, suscitando novas imagens reflexivas do indivíduo e da sociedade. Se, nalguns dos seus aspectos, a pós-modernidade se apresenta como a expiração da utopia iluminista, é crível que provoque um sentimento de fractura e «crise», pelo facto de se tornarem caducas muitas das nossas representações sociais e discursos. Sem atribuir a esta crise quaisquer contornos apocalípticos, mas procurando aprofundá-la no próprio questionamento crítico-reflexivo que suscita, diríamos que somos hoje remetidos para novos desafios no domínio educativo que se perfilam tanto ao nível das práticas como dos discursos metateóricos que justificam as intenções praxeológicas. 


\section{Da modernidade à pós-modernidade: a fractura das racio- nalidades e as metamorfoses do tempo e da razão}

Se a vivência pós-moderna marca a nossa contemporaneidade, a suspeita 249 metafísica que desagrega as possibilidades de conceptualização de uma razão unitária na filosofia moderna, advém da própria acção demolidora de Nietzsche que erradica, com a tão proclamada «morte de Deus», qualquer fundamento transcendente que corporize a unidade do plano ôntico e fenomenal. Perdidas as referências ontológicas que figuravam como 0 sustentáculo da nossa ordenação do tempo e da razão, somos projectados, sem remissão, para a pluralidade dos discursos que se fragmentam e reverberam sem 0 princípio unificador que os fazia transcender a contingência temporal das suas formulações. Nos dédalos inseguros do niilismo que nos aprisionam na vertigem do instantâneo temporal, a morte de Deus ameaça clonar-se e replicar-se na do próprio sujeito humano, cuja vida se funcionaliza e instrumentaliza no mero âmbito das actividades que ele próprio cria e a que se consagra, na fugacidade da instantaneidade que 0 devora. Se não é, pois, difícil antecipar os percursos pós-modernistas nas reflexões de Nietzsche, conseqiiente é perceber que «a morte de Deus» é, no plano lógico, a da racionalidade que 0 mesmo sustenta e que, a partir do momento em que se extingue a referência escatológica a um projecto humano comum e a Razão forte se torna débil, por ausência de fundamento intemporal, desagrega-se 0 sentido de uma humanidade convocada para uma história com uma vocação partilhada.

Tornados órfãos da transcendência, pela acudíante lucidez do filósofo, não podemos mais vislumbrar uma intencionalidade para a História fora do espaço da sua própria narratividade,de sorte que 0 entrecruzamento do jogo plural dos discursos se configura como o topos de aperfeiçoamento e formatação da racionalidade débil que passa a constituir a matriz onto-antropológica do nosso fazer temporal.Com efeito, perdido o sentido de ordenação de um tempo em relação a um fim transcendente, a assunção da 
relatividade contingencial da razão torna-se 0 próprio eixo ordenador da reflexividade irreversivelmente fragmentada por ausência de um princípio unitário. E a «morte de Deus» que foi anunciada confirma-se, também, como a morte de «uma história pré-anunciada», porque 0 sentido da unidade da história se dilui, na ausência de um princípio transcendental que a ordene no seu sentido permanente e estável. Para Gianni Vattimo (1991), a modernidade tem 0 seu epílogo quando se erradica a possibilidade de conceber a história humana de forma unitária. Verdade é que, no movimento de secularização da cultura, que estrutura e funda a configuração cultural da modernidade, na hipostasiação que é feita da noção de Progresso ressoam ainda os ecos do eterno sagrado que, na sua versão laica, orienta 0 devir humano.Perdido 0 sentido da ordenação do tempo em relação a um fim transcendente, a circunstância contingencial torna-se a exclusiva referência que pode demarcar os parâmetros da acção humana e 0 sentido da própria história colectiva. Se a «morte de Deus» que foi anunciada se confirma, assim, a longo termo, como a morte de uma «história pré-anunciada», é porque a própria unicidade da história se dilui na ausência de um princípio escatológico que a regule. A fragmentação desta visão unitária do tempo que percorre toda a vivência pós-moderna implicita, na perspectiva de Lyotard (1989), o fim das grandes metanarrativas que corporizavam a união de uma tessitura conjuntural de acontecimentos, aparentemente desconexos, nas suas ocorrências díspares.

0 luto por estes discursos legitimadores da racionalidade moderna, contestados na sua pretensão totalizante e universalista, tornam errático 0 caminhar histórico do sujeito pós-moderno, que a si mesmo se representa, como um figurante amnésico da História. Nesta deriva heteróclita de sentidos que a tecnologia ameaça fazer proliferar, alterando as nossas habituais referências ao espaço/tempo e à identidade do próprio corpo, a episteme herdada da racionalidade moderna flexibiliza-se e transmuta-se. E a perda de densidade ontológica dos mundos virtuais faz vislumbrar como sedutoras as possibilidades instrumentais dos novos meios tecnológicos que podem criar e recriar mundos à medida das nossas fantasias narcísicas. 
Se a pós-modernidade se afirma, a muitos títulos, como urna nova paisagem cultural, tal facto advém, sem dúvida, da multirreferencialidade de coordenadas com que se defronta 0 pensamento pós-moderno. A verdade é que se 0 movimento de globalização económica e cultural ameaça erodir a diversidade plural dos discursos e as novas tecnologias comunicacionais operam uma deslocalização que dilui a referência identitária aos espaços geográficos, certo é também que, dificilmente, poderíamos considerar a expansão desta racionalidade tecno-instrumental como a simples figuração de uma racionalidade moderna submetida à hierarquia dos seus símbolos e valores. Com efeito, se aparentemente as utopias tecnológicas modernas parecem favorecer uma crescente flexibilização e subjectivação dos procedimentos instrumentais, por outro, consumam um processo de desrealização dos sentidos subjectivamente construídos, pela antecipação de um universo virtualmente programado de objectivação hermenêutica dos sujeitos. Se 0 sujeito translocal se sucede, assim, ao sujeito pretensamente universal da concepção moderna, tal só se torna possível mediante uma técnica e uma economia que sustentam 0 processo de globalização, deslegitimando os processos de construção identitária dos sujeitos a partir das suas ligações e práticas nas comunidades envolventes. Se a historicidade operava, desta feita, na interdependência factual dos discursos e acções, e as racionalidades veiculavam representações imbuídas da corporeidade dos sujeitos «dialogantes», as novas tecnologias suscitam a criação de espaços pretensamente «neutros» que reificam 0 pensamento e só aparentemente favorecem 0 hibridismo cultural. Nesta nova concertação cultural, torna-se evidente a diluição da razão argumentativa dialogante, mediante a qual a alteridade dos discursos se confronta e disputa, no esclarecimento mútuo dos seus pressupostos. Nas distintas paisagens etnoculturais, à concatenação dos argumentos racionais susceptíveis de serem rebatidos prefere-se a violência das acções fortemente mediatizadas pelas tecnologias que anulam as distâncias e podem tornar pluritópicos os efeitos dos comportamentos locais. Se 0 fim anunciado da História desemboca, assim, em novas figurações de 
conservadorismo político e em insuspeitas violências, por irrupção do global no local e do local no global, é tempo de repensarmos a normatividade que possa figurar como legitimadora de uma teoria da educação, num tempo em que paradoxalmente se assiste a uma homogeneização cultural e a um debilitamento da Razão. Neste sentido, e face aos novos desafios que se perfilam à educação, haverá que reformular 0 discurso pedagógico não só no referente à sua dimensão pragmática e tecnicizante, mas, também, repensando-o na sua dimensão teleológica.

3. As exigências normativas de uma teoria da educação face aos desafios contemporâneos

$\mathrm{Na}$ verdade, se as metanarrativas que corporizavam 0 pensamento da modernidade perderam, hoje, o carácter fundacional, é facilmente admissível que 0 próprio discurso pedagógico reflicta 0 ímpeto da fractura epistemológico-axiológica que fez abalar 0 paradigma racionalista que 0 configurava. Não podemos olvidar que 0 esforço emancipador das Luzes que pretendia promover a autonomia moral dos sujeitos se projectou pedagogicamente no movimento da Educação Nova. Sem desertarmos, assim, do entusiasmo então florescente pela edificação de uma escola renovada, temos de reconhecer que 0 novo contexto societal com acrescidas exigências económico-tecnológicas que tornam 0 mercado de trabalho mais concorrencial e a emergência de uma escola mediática paralela envolvem desafios ignotos para o processo educativo e dão acuidade a antinomias que, figurando como omnipresentes na pedagogia, se agigantam na fractura das racionalidades que a pós-modernidade consumou. Com efeito, as antinomias que percorrem 0 discurso reflexivo sobre a educação e tendem a configurá-lo como «socialização» versus processo de autonomização reactivam-se nas ameaças crescentes de atomização social que 0 neoliberalismo económico 
fomentou. Como, enfaticamente, se questiona Savater (2000, 6): «A educação deve preparar concorrentes adaptados ao mercado de trabalho ou formar homens completos? Deve reforçar a autonomia de cada indivíduo, muitas vezes critico e dissidente, ou manter a coesão do conjunto da sociedade?

Deve desenvolver a originalidade inovadora ou a identidade tradicional do grupo? Deve polarizar-se sobre a eficácia prática ou ficar no risco criador ?» E a verdade é que se 0 próprio processo de modernização potenciava já riscos inerentes à autonomização dos indivíduos, é na fragmentação identitária do tempo presente que tais riscos se denotam e extremam. Na perspectiva de Alain Renault $(1998,48)$, «dado que 0 retrocesso moderno das tradições nos privou de qualquer referência a indicações comuns predeterminadas, cada um de nós deverá ímpôr-se um processo contínuo de fundamentação e de revisão das normas a que se sujeita». Se a radicalização do individualismo se afirma, pois, como a marca e 0 risco do tempo presente, por debilitamento da referência a valores colectivamente partilhados, torna-se imperativo que, no repúdio por visões totalizantes e monolíticas, os discursos pedagógicos recusem uma relativização axiológica que tornaria infundado 0 próprio sentido da educação. Deste ponto de vista, não podemos deixar de conferir um sentido ético à educação que se contrapõe à «falácia da neutralidade axiológica» da Escola.

A concepção de educação moral funda as suas raízes na tradição grega. Entendida como formação do carácter, a educação moral toma por horizonte 0 serviço à comunidade (polis), sendo esta referência que torna inteligível a sua própria substantividade. Porquanto se a cidadania é uma condição jurídica dos indivíduos, mediante a qual o Estado reconhece e garante um conjunto de direitos, a sua configuração substantiva vai exigir, por parte dos indivíduos, a adesão a valores e padrões normativos que possibilite a assunção dos deveres para com a comunidade. Se a formação ética para 0 exercício da cidadania corporiza, desde 0 horizonte da cultura grega, um imperativo maior da própria educação, é óbvio que haverá que reinterpretar as condições deste exercício nas configurações materiais da sua própria 
historicidade local. Ademais, haverá que recordar, igualmente, que na etapa histórica em que a Escola foi delineada como uma instituição laica da responsabilidade do Estado, a sua mensagem socializadora assumiu um papel fundamental na génese dos modernos estados europeus, contribuindo para a consolidação das identidades nacionais, através da unificação da língua, da cultura e das mentalidades.Se os desafios que se perfilam à instituição escolar são, hoje, de outra natureza, haverá que tematizá-los na confluência das novas pressões societais e dos distintos parâmetros vivenciais e reflexivos da pós-modernidade.

No marco das exigências sócio-históricas que singularizam a nossa época e se repercutem directamente no âmbito reflexivo da teoria da educação, podemos salientar como relevantes: a crescente planetarização propiciada pelos meios tecnológicos de informação e comunicação; a crescente multiculturalidade das sociedades, resultante de fluxos migratórios; a crescente importância do conhecimento como fonte de produtividade económica. 0 carácter estruturante destes três parâmetros tem vindo a direccionar as actuais sociedades no sentido de uma crescente globalização que podendo remeter-nos, num sentido mais utópico, para um modelo identitário de planetarização, implícita também os riscos inerentes a uma potencial hegemonia dos poderes económicos transnacionais que escapam ao controlo dos Estados. Por força destas pressões económicas de um mercado laborai mundializado, tanto quanto dos organismos educativos internacionais, emerge um modelo «globalizado» da educação que tende a impor-se, formatando uma configuração «normativa» dos objectivos e conteúdos pragmáticos dos planos curriculares. Evidentemente que a emergência deste fenómeno de globalização que tem uma tradução a nível da educação é correlativo do próprio desenvolvimento das novas tecnologias da informação que permitem a comunicação imediata entre sujeitos e organismos situados em espaços geográficos distanciados.

De modo significativo, as novas tecnologias da informação, que têm vindo a transmutar os estilos de aprender e ensinar, viabilizam modalidades 
de aprendizagem que ultrapassam largamente os limites espácio-temporais das instituições escolares e envolvem a massa dos cidadãos num processo individualizado e contínuo de formação ao longo da vida.

Num mundo em homogenização comunicacional, por efeito das próprias tecnologias, mas em que a desmultiplicação e heterogeneidade dos discursos debilita a razão configuradora do nosso próprio entendimento sobre as sociedades e 0 devir em gestação, tornar-se-á cada vez mais difícil identificar os padrões axiológico-normativos que podem erigir-se como pilares fundacionais de urna teoría da educação. $\mathrm{Na}$ «sociedade do conhecimento» que se delineia, e em que a expansão das novas tecnologias potenciam virtualidades cada vez mais ampias para 0 processo educativo das massas, reduzindo 0 impacto da equação pessoal no processo de formação, não podemos deixar de repensar a utopia que terá necessariamente de polarizar os vários discursos metateóricos em torno da educação. Reconheça-se ou não, de forma explícita, 0 acto educativo é sempre configurado no horizonte de uma utopia, entendendo nós que a utopia é um olhar projectado no futuro, que nos vincula na obrigação dos nossos compromissos presentes. No fio narrativo em que 0 passado e 0 futuro se entretecem na actividade presente, afigura-se-nos urgente que, na continuidade das utopias educativas que formataram a modernidade, se recrie no actual contexto da pós-modernidade, um novo humanismo pedagógico que dilate e reformule os marcos referenciais que tipificaram o projecto educativo moral e cívico da modernidade.

A verdade é que, complementarmente à expansão das modalidades educativas, as novas tecnologias podem ser usadas como suporte para fomentar nos educandos uma mais vasta consciência cívica, através de um sentido de planetarização que se procura inculcar através da participação em redes de solidariedade transnacional. Não escamoteando 0 risco que representa para as liberdades individuais 0 crescente poder expansionário das fontes económicas, haverá que reconhecer que só pela construção de formas de cidadania activa, a nível local e global, as democracias 
se podem corporizar, rebatendo os efeitos centrípetos e aglutinadores dos novos poderes mediáticos e económicos susceptíveis de triturar as identidades culturais, historicamente afirmadas. Convém não esquecer que, nos princípios do século XX, a Pedagogia científica se consolidou, por acção do movimento da Educação Nova, que se regeu nas suas intenções e práticas por objectivos de reforma social. Pretendendo fundamentar a sua prática pedagógica nas teses psicológicas emergentes sobre a criança, a Escola Activa fomentou de modo explícito uma ruptura epistémica com os modelos pedagógicos tradicionais que se revelavam inadequados ao sentido de progresso que a sociedade conhecia nos primórdios do século XX.

Esta ruptura, que assinalava uma intenção objectiva de operar uma transformação na escola e na sociedade, foi consumada, quer em nome da cientificidade positivista, quer por assunção de valores iluministas como os da liberdade e autonomia moral dos sujeitos. 0 exemplo do Instituto Jean Jacques Rousseau é, a este respeito, paradigmático, porque denota um esforço intelectualmente rigoroso para desenvolver experiências fidedignas de pedagogia experimental, fundando-se sobre dados empíricos da Psicologia, mas ao mesmo tempo todo o esforço educativo tem um fim político e moral. De forma explícitamente assumida, a cientificidade que consagra os estudos de Bovet e Chaparède concilia-se sempre com intenções praxeológicas, ao nível de uma reforma social. Neste sentido, a sua revolução pedagógica afirma-se como prenúncio de uma nova ordem social que concilia a autonomia da pessoa com a normatividade social prescrita pela concertação dos interesses individuais dos cidadãos.

Diferindo para a conjuntura presente 0 gigantismo dos desafios com que se confrontou a sociedade, nos alvores do passado século, torna-se evidente que a mensagem socializadora da educação tem de ganhar contornos de uma peleja em favor de uma racionalidade normativa que incorpore no novo contexto sócio-histórico, o que de mais depurado a vocação ilustrada da modernidade nos legou. É neste sentido que qualquer reflexão metateórica, em torno da educação, tem de se configurar, nas exigências de um novo 
«humanismo» pedagógico, capaz de recuperar, nos estilhaços de uma razão pos-moderna fragmentada, a lucidez crítica que lhe permita não trair as esperanças utópicas, sempre renovadas na educação. 
Anderson, P. (1999). As origens da pós-modernidade. Rio de Janeiro: Zahar Editores.

Arregui, J.V. (2004). La pluralidad dela razón. Madrid: Editorial Síntesis.

Cantista, M.J, (1984). Racionalismo em crise. Porto: Livraria Civilização Editora.

Formosinho, M. D. (2001). Para o repensar de uma ética cívica nas escolas. Fragmentos da Cultura, vol. 11 (4), Jul-Ag. Universidade Católica de Goiás, pp. 687-692.

Formosinho, M. D. (2003). «Reencontrar um novo estatuto para a educação. Do comentário a algumas reflexões». In Revolucão das idéias e teorias pedagógicas. I Congresso da Secção de Filosofia da Educação da Sociedade Portuguesa de Ciências da Educação. Castelo Branco: Edição Alma Azul.

Formosinho, M. D. \& Boavida, J. (1999). «Náufragos» ou «astronautas»? Pós-modernidade e educação, Revista Portuguesa de Pedagogia, Ano XXXIII, nº 1, pp. 5-17.

Formosinho, M. D. \& Boavida, J. (2002). «Educación, Ética y Posmodernidad». Educación XXI, n. ${ }^{\circ} 4$, pp. 167-187.

Giddens, A. (1994). Les conséquences de la modernité. Paris: Éditions L'Harmattan.

Heather, D. (1999). What is citizenship? Oxford: Polity Press.

Gore, J. M. (1996). Controversias entre las pedagogias. Madrid: Morata.

Peace, N. \& Hall-Garten, J. (eds.) (2000). Tomorow's citizens. Criticai debates in citizenship and education. London: Institute for Public Policy Research.

Pereira, M. B. (1990). Modernidade e tempo. Para uma leitura do discurso moderno. Coimbra: Livraria Minerva.

Renaut, A. (1998). El futuro de la ética. Barcelona: Galáxia Gutenberg.

Roa, A (1995). Modernidad y posmodernidad. Coincidências y diferencias fundamentales. Santiago do Chile: Editorial Andrés Bello.

Savater, F. (2000). Pour l'éducation (tradução francesa de H. Gisbert). Paris: Éditions Payot. 